\title{
Depression in childhood
}

\author{
1 Drugs may be useful \\ C A Kaplan
}

The current state of assessment, classification, and treatment of depression in childhood has been actively debated over the past 20 years. Views have varied over time and from country to country, and controversy still persists.

The most widely accepted approach to the treatment of depression in childhood is psychotherapeutic. The rationale for this, however, needs closer consideration as does the basis for claiming therapeutic efficacy. The place of drugs in the treatment of childhood depression similarly needs elucidation. Currently a wide range of therapeutic interventions is used to help depressed children and adolescents, but neither an optimal regimen nor effectiveness has yet been shown.

\section{... The rationale for the use of antidepressant drugs remains compelling.}

To judge the efficacy of treatment, homogeneity between groups is necessary, and this depends on a reliable classification system. Several different systems have been proposed, ' but an important problem is the variation of presentation with age, particularly before and after puberty. Diagnostic criteria need to be developed that account for the child's developmental stage, ${ }^{2}$ although some authors argue that the basic phenomenology remains the same from childhood into adulthood. ${ }^{3}$

\section{Management}

The approach to management of depression in childhood may be considered in stages. Firstly, a detailed assessment of the whole child and his or her family and general environment is needed. The place of drugs in the management of the patient depends on this assessment. Initially, psychological strategies are used to relieve stress and improve the level of support offered to the child. Simple methods such as offering remedial help with school work, improving methods of family functioning, and working with the individual child to help him or her deal with stress more effectively are all potentially beneficial. ${ }^{4}$ These types of intervention rest on psychodynamic approaches and are generally accepted as the first line strategy in dealing with children who present with depressive disorders. The efficacy of such interventions, however, is yet to be shown experimentally.

Clinically, drugs are usually reserved for more seriously depressed patients in whom the depression of mood is severe and persistent and accompanied by a decrease in energy or by agitation. Few child psychiatrists would prescribe antidepressants to children under the age of 10 years, and drugs are always used in combination with counselling and psychotherapy, which is usually more intensive than that for more mildly affected children. The evidence for recommending antidepressant treatment needs to be examined as its role is not yet fully established and much controversy surrounds the use of such drugs.

\section{Use of antidepressants}

If the changes in biogenic amine metabolism that occur in children and adolescents with major depressive disorder are analogous to those that occur in adults then drugs that alter this metabolism should restore normal mood. Little, however, is known about the biochemical changes associated with mood alteration in childhood: biological correlates such as sleep patterns on electroencephalography are not identical and knowledge of pharmacodynamics and pharmacokinetics in children is limited. In addition, antidepressants are used in several differing conditions in childhoodfor example, enuresis, hyperkinesis-in which the underlying mechanism is not postulated to be antidepressant in nature. Added to these difficulties are the side effects associated with the use of antidepressants. With tricyclic antidepressants these include dry mouth, blurred vision, postural hypotension, constipation, nausea, and in high doses a cardiotoxic effect, and careful monitoring is of course essential. Despite these difficulties child and adolescent psychiatrists do use drugs in treating severe depression.

Several studies have evaluated the use of antidepressant drugs in prepubertal children. Some have reported
Fleming Nuffield Unit, Newcastle upon Tyne NE2 3AE

C A Kaplan, MRCPSYCH, consultant in child psychiatry

Br.Med F 1990;300:1260-1

\section{EDITORIAL COMMENT}

Depression in childhood is poorly understood and inadequately researched. Even the existence of biological depression in this age group is contentious, and treatment strategies are clearly empirical. Clinical pharmacology in children is a subject of considerable ignorance, although for certain drugs pharmacokinetic changes have been shown, with these changes themselves altering during the childhood years. Detailed pharmacokinetic and, more importantly, pharmacodynamic studies on antidepressants have not been carried out in children, and both authors point to the difficulty of establishing the balance of benefit to risk when so little basic information is available. Psychotherapeutic intervention in any age group is difficult to assess experimentally and, as in the case of drug treatment, definitive studies are lacking. Controversy thrives where there is insufficient knowledge, and both authors clearly illustrate the need for more high quality research in child psychiatry. The take home message for the rest of us is that this is a highly specialised subject in which expert advice is needed with regard to both diagnosis and treatment. PETER C RUBIN, professor of therapeutics, University of Nottingham 
high response rates ${ }^{5}$ or evidence of a relation between plasma concentrations of drugs and clinical response ${ }^{6.8}$ These studies have, however, been criticised, on the basis of design difficulties, small sample size, and lack of placebo control. In a more recent double blind placebo controlled study of 53 children, plasma concentrations of drugs were linearly associated with clinical response, but overall the results did not support the hypothesis that imipramine is effective in prepubertal depression. ${ }^{9}$

Two controlled studies have examined the effectiveness of tricyclic antidepressants in major depression after puberty. ${ }^{1011}$ Both studies had limitations, and neither showed evidence of efficacy of drug treatment. Thus, at best, adolescents with major depressive disorders show a partial response to tricyclic antidepressants. A recent study of adolescents with depression refractory to tricyclics showed a high response rate to treatment with monoamine oxidase inhibitors, strongly suggesting the need for further research in this age group. ${ }^{12}$

Thus, to date, an improvement in assessment and classification of major depression in young patients, combined with increased rigour of research methods, seems to have challenged the earlier optimism about the use of antidepressants in this group. The rationale for the use of these drugs remains compelling, however, and active research continues. There is a great need for well designed studies on this subject.

\section{Other treatments}

The use of drugs is only one of the therapeutic strategies available. What evidence is there that other strategies are effective? Psychodynamic treatments include individual psychotherapy, family therapy, group therapy, cognitive therapy, and others. They are widely used and good results are claimed. It must be borne in mind, however, that there is a high spontaneous remission rate in childhood depression and there are many difficulties in teasing out the differences between this and the response to treatment. The underlying psychodynamic theories are described in detail, but there is a paucity of controlled outcome studies of any standing, and the lack of information on this subject is as great as, if not greater than, that on drug treatment.

\section{Conclusions}

Thus in conclusion I agree that the first line of intervention should be a trial of psychological forms of treatment, but I think that in older, severely affected children or those who remain significantly depressed over several months a trial of drugs with careful monitoring should not be denied to the patient. This "physical" form of treatment must, of course, be seen as only one part of a complex strategy that entails many different forms of intervention, and, in addition, it should be given only for a limited time. Drug treatment should not be seen as a "cure" for depressive disorder but as a helpful part of a multifaceted intervention strategy for severely depressed children and adolescents.

1 Cantwell DP. Depressive disorders in children: validation of clinical svndromes. Psychiatr Clin North Am 1985;8:779-92.

2. Kendall PC, Cantwell DP, Kazdin AE. Depression in children and adolescents: assessment issues and recommendations. Cognitive Therapy and Research 1989;13:109-46.

3 Carlson GA, Kashani JH. Phenomenology of major depression from childhood through adulthood: analysis of three studies. Am $\mathcal{F}$ Psychiatry 1988;145: 1222-5.

4 Graham P. Child psychiatry: a developmental approach. Oxford: Oxford University Press, 1986.

5 Frommer EA. Treatment of childhood depression and antidepressant drugs. BrMed F 1967;i:729-32.

6 Antich JP, Perel JM, Lupatkin W, Chambers W, Tabrizi MA, Stiller R Plasma levels of imipramine and desmethylimipramine and clinical response in pre-pubertal major depressive disorder: a preliminary report. fournal of the American Academy of Child Psychiatry 1979;18:616-27.

7 Preskorn SH, Weller RA, Glotzbach E. Plasma levels of imipramine and adverse effects in children. Am $\mathcal{F}$ Psychiatry 1983;140:1332-5.

8 Geller B, Perel JM, Knitter EF, Lycaki H, Farooki ZQ. Nortriptylline in major depressive disorder in children. Psychophyrmacol Bull 1983:19:62-4.

Antich JP Perel JM Lupatkin W et al Imipumine in prepubertal major depressive disorders. Arch Gen Psychiatry 1987;44:81-9.

depressive disorders. Arch Gen Psychiatry 1987; $44: 81-9$.
10 Kramer AD, Feiguine RJ. Clinical effects of amitriptylline in adolescent depression. F Am Acad Child Adolesc Psychiatry 1981;20:636-44.

11 Ryan ND, Antich JP, Cooper T, et al. Imipramine in major adolescent Ryan ND, Antich JP, Cooper T, et al. Imipramine in major adolescent
depression: plasma level and clinical response. Acta Psychiatr Scand depression: plas
1986;73:275-88.

12 Ryan ND, Antich JP, Rabinovich $\mathrm{H}$, et al. MAOI's in adolescent major depression unresponsive to tricyclic antidepressants. $\mathcal{J}$ Am Acad Child Adolesc Psychiatry 1988;27:755-8.

\section{Child and Family \\ Psychiatric Service, \\ Vale Drive Clinic, Barnet, Hertfordshire EN5 2ED \\ Robin Anderson, \\ MRCPSYCH, consultant child psychiatrist}

BrMed J 1990;300:1261-2

\section{2 A psychoanalytic approach Robin Anderson}

Psychoanalysts have been interested in depression as a state of mind for many years ${ }^{1}$ and have continued to hold the view that despite the findings of neurobiological research there is much to be gained in continuing to try to make sense of patients' experience. They find important patterns of thoughts and feelings and ways of relating to others, even in patients with an obviously biological predisposition to depression, that seem convincingly to make sense of why patients feel as they do; moreover, many such patients have been considerably helped by psychoanalytic treatments. (I will not discuss the possible mechanism by which the mind and body interact with each other, but in depression I think a close encounter between psychobiological and mental life is found in which both unite to create the patient's state of mind in ways that are at present largely mysterious (but see Taylor ${ }^{2}$ ).)

\section{Separateness and loss}

Freud in his classic paper "Mourning and melancholia" compared and contrasted these two states of mind. He noticed that, although melancholia is often precipitated by loss, melancholic patients are pre- occupied in a complaining, self critical, guilty way with themselves. Many of the characteristics most complained about, however, clearly resembled important people in the patient's life-for example, a spouse or a parent. He concluded that such patients are unable to face loss properly, especially when the relationship to the lost figures is an ambivalent one, instead living out a fantasy or, in those who are severely depressed, a delusion that the lost figures exist inside themselves, where they continue to persecute and preoccupy them.

This seminal work of Freud's was later put into a developmental context by subsequent workers and provides the basis for depressive psychopathology. From the time of weaning, and even before, there is a gradual development of the capacity to face the reality of separateness and loss. When this is unbearable infants and young children have ways of denying it, which are based on the fantasy or illusion that they and their loved object are not really separate but can inhabit each other in various ways. If development proceeds satisfactorily there will be a greater sense of separateness together with an inner security that allows this separateness to be tolerated. This occurs in the context of the mother-infant relationship and requires the mother to 